Revista Iberoamericana, Vol. LXXI, Núm. 210, Enero-Marzo 2005, 23-33

\title{
NARRACIONES FEMENINAS DE MEMORIA Y RESISTENCIA. POLITICA Y ÉTICA EN LA LITERATURA LATINOAMERICANA EN EL FIN DEL SIGLO XX
}

POR

Ana María Amar Sánchez

University of California, Irvine

Este trabajo forma parte de una investigación sobre los vínculos entre literatura, historia, política y ética en la narrativa latinoamericana de los últimos cuarenta años. En particular, una de sus líneas se ocupa de aquellos relatos en los que la posición de perdedores de los protagonistas es el resultado de una elección ético-política, desde la cual se preserva la memoria del pasado y se lee la historia y el presente latinoamericanos.

El corpus analizado en principio incluyó un conjunto de textos de los últimos treinta años del siglo xx relacionados entre sí por sus representaciones de héroes "perdedores”. Es cierto que muchos de los relatos considerados se refieren de alguna manera al exilio y la diáspora latinoamericana de los años setenta; sin embargo el foco de mi interés está en cómo han constituido una metáfora de la historia, que siempre funciona como un telón de fondo, a través de la figura del antihéroe. En especial, son relatos que proporcionan, de diversos modos, una respuesta y representan soluciones imaginarias a la pregunta sobre cómo vivir, qué hacer cuando nuestra historia se quebró y debemos sobrevivir entre los ganadores. Es decir, son lecturas y representaciones de mundos marcados por el trauma de diversas derrotas políticas. En este sentido, el interés de este trabajo no se concentra en las llamadas “novelas de la dictadura”, ${ }^{1}$ aunque puede incluir alguna eventualemente, sino en los relatos que luego de la pérdida proponen modos de leerla y convivir con ella. Se trata de ficciones ligadas a coyunturas muy precisas en las que la metáfora del fracaso constituye una mirada y una evaluación sobre ese período histórico. Nos encontramos entonces frente a un conjunto diverso de textos, en los que la historia no ingresa a través de héroes y episodios conocidos, precisos, en los que se da una versión diferente de la oficial; sino frente a relatos que sólo tienen una relación "sesgada” con la coyuntura histórica. Sin embargo todos representan (y proponen) una posición ética y política frente a los hechos, ya no por medio de una perspectiva narrativa o de una lectura particular de la Historia, sino gracias a las figuras ficcionales, héroes o antihéroes que asumen el camino de la pérdida como actitud ética y como única postura política con que enfrentar la Historia.

\footnotetext{
${ }^{1}$ La mayoría de los críticos suelen leer la literatura latinoamericana relacionada con las dictaduras de los últimos treinta años desde la noción más obvia de "derrota política” y fracaso de un proyecto histórico, estableciendo una relación poco mediatizada entre el texto y los hechos históricos. Pueden verse como ejemplo los trabajos de Scheines y de Avelar.
} 
El corpus se conformó "naturalmente" en principio por relatos escritos por autores y con héroes (o antihéroes) también masculinos. De hecho, surgió de mi trabajo anterior sobre literatura policial ${ }^{2}$ y se amplió con otras novelas como El viaducto de Darío Oses, El jardín de al lado de José Donoso, Morir en Berlín de Carlos Cerda, y relatos no policiales de Juan Sasturain y de Paco Taibo II, entre otros. En verdad, podría construirse con ellos una saga que desde Respiración artificial (1980) culmine en El viaducto o Arcángeles. Doce historias de revolucionarios herejes de Taibo II (1998). En todos, contar la Historia sin contarla y a través de una metáfora es un modo de asumir la derrota, una opción frente a los hechos, un propuesta para situarse frente a ellos.

Frente a este corpus, la pregunta sobre la ausencia de narradoras (y heroínas) surgió inevitablemente. ¿Cómo han construido los relatos femeninos del mismo período una metáfora de la pérdida? ¿Proponen ellos análogas representaciones del héroe/heroína perdedor/a? ¿Plantean las mismas resoluciones imaginarias frente a la derrota histórica en las coyunturas en las que transcurren? ¿Sugieren similares estrategias de resistencia al olvido y de afirmación de la memoria? Es decir, ¿los relatos femeninos se pliegan y participan del mismo sistema de representaciones de los otros textos ("masculinos”) del corpus o abren alternativas específicas en su lectura de la historia y de la derrota?

La línea divisoria entre narrativas femeninas y masculinas (que quizá no sea necesariamente una división entre escritoras y escritores ${ }^{3}$ ) resulta problemática en un caso como éste en que se debaten formas de representación ligadas con la historia y la política. La inclusión de estos relatos provocó algunas sorpresas: no parece abundar el mismo tipo de héroes o heroínas en los textos escritos por mujeres. Si bien este estudio no tiene ninguna pretención de exhaustividad, ni intenta establecer "leyes generales”, puede verse con qué facilidad se encuentran textos masculinos para incorporar al trabajo y, por contrapartida, la dificultad de incluir narradoras.

En primera instancia se hace necesario aclarar el sentido fundamental que adquiere el perder en los relatos considerados: en un mundo corrupto donde los gobiernos son responsables de los crímenes y las leyes protejen a los asesinos el triunfo siempre es sospechoso; sólo es posible cuando se ha pactado y se han aceptado connivencias con el poder. Por eso el protagonista de la novela Nombre de torero de Luis Sepúlveda señala “sé perder, y en estos tiempos eso es una gran virtud”. Perder resulta así una forma de triunfo que ubica a los protagonistas más allá del sistema y les proporciona otra clase de éxito. Ser un antihéroe perdedor, formar parte de los derrotados garantiza pertenecer a un grupo superior de triunfadores: el de los que han resistido y fundan su victoria en la orgullosa aceptación de la derrota. Habría que entender que esta aceptación de la pérdida no consiste en una vocación por el fracaso; por el contrario, estar entre los perdedores, no ceder, es alcanzar otra dimensión del triunfo.

Se impone recordar aquí cómo insiste Alain Badiou en ligar la ética a la política. No hay ética en abstracto, sostiene el filósofo francés, toda ética está en situación y se define

2 Ver el capítulo "El crimen a veces paga. Policial latinoamericano en el fin de siglo" (Amar Sánchez).

${ }^{3}$ Las definiciones y delimitaciones entre "literatura escrita por mujeres" y/o "narrativa femenina" suele producir confusiones, debates y mal entendidos. Utilizaré aquí los términos de forma indistinta a sabiendas de su problemática condición. 
de acuerdo a la política a la que pertenece. Si puede hablarse de una "ética de las verdades" es con respecto a los sujetos en esa situación precisa que él llama acontecimiento. La ética es entonces fidelidad del sujeto a una verdad que siempre excede la opinión o el sentido común de una época. Badiou propone una ética de la convicción, y en eso consiste su noción de resistencia, en las antípodas de la capacidad de adaptación. La convicción es ese empecinamiento capaz de atravesar las condiciones más adversas, capaz de llevar a la aceptación de la muerte, el olvido, la soledad, los márgenes. Si el no ceder es un principio clave de la ética, podría pensarse que los protagonistas del corpus lejos de ser fracasados son héroes éticos. Puesto que ceder, resignarse, pactar, es perder la dignidad y la identidad, la exigencia es persistir, continuar a pesar de las circunstancias adversas. Es interesante que Badiou considere el fracasar como una categoría política y el ceder como una categoría ética: de este modo, desde su perspectiva, el único héroe posible es aquel cuyo triunfo consiste en no haberse traicionado y no haber cedido frente a los "vencedores". Personajes como los de Perder es cuestión de método o El viaducto, ${ }^{4}$ no se han resignado ni pactado; poseen, por el contrario, lo que Badiou denomina una ética “prometeica”, que, a la inversa de todo pacto con el presente, se juega por un porvenir. En la medida en que pactar con ese presente victorioso es olvidar el pasado y traicionarse a uno mismo, la "fidelidad a una verdad" 5 es una forma de la memoria, de la lucha por su conservación. No pactar es recordar, sostener un proyecto que se juega, contra toda garantía, por esa verdad; de ahí la íntima ligazón entre ética y política en el pensamiento de Badiou. ${ }^{6}$ Por lo tanto los héroes y heroínas que aquí interesan encarnan, mejor que muchos ensayos teóricos, una respuesta ética y un proyecto de acción frente a las derrotas históricas latinoamericanas de los últimos años. Estos héroes resisten, recuerdan y no aceptan el olvido; por eso mismo, no pactan con los vencedores que “suelen ser repugnantes” (Vázquez Montalbán).

¿Cómo sostener el recuerdo? ¿Cómo mantener la memoria viva? Los textos parecen debatir este conflicto y proponer un camino, una resolución imaginaria que contradice las soluciones propuestas por los vencedores en el mundo real. Los héroes "memoriosos" recuerdan la historia de los vencidos y se reconocen como perdedores, porque como dice Reyes Mate "sólo recuerdan los sobrevivientes, [...] no es el recuerdo de los vencedores sino el de los vencidos el que crea la esperanza” (224, la bastardilla es del autor). El éxito de los vencedores construye el presente y borra el pasado; sólo cuando se hace valer este pasado de los vencidos y se lo incluye, la ética puede ser política. Es decir, sólo cuando

\footnotetext{
${ }^{4}$ En esta última novela el protagonista duplica a figuras políticas reales, especialmente al presidente Salvador Allende, paradigma del político que no cedió y llevó su "ética de la convicción” a las últimas cosecuencias.

5 "Se llama "verdad" (una verdad) al proceso real de una fidelidad a un acontecimiento. Aquello que esta fidelidad produce en la situación [...]” (125). Según señala Badiou, es con respecto a los sujetos, que son las circunstancias locales de un proceso de verdad, que puede hablarse de una "ética de las verdades”. La bastardilla es del autor.

${ }^{6}$ Sin embargo, muchos ensayos dan cuenta de las dificultades que plantea el vínculo entre política y ética para la mayoría de los especialistas. Compilaciones tan diferentes como las de Hoyos, Vásquez y Uribe o la de Garber, Hanssen y Walkowitz, “divorcian” los términos, oponiendo “especulación vs. acción” en el primer caso o refugiándose en un enfoque académico de la cuestión en el segundo.
} 
se cuestiona un presente construido sobre los cadáveres del pasado se practica lo que puede llamarse una ética de la convicción. ${ }^{7}$ Asumir el camino de los perdedores como única conducta ética posible, ser consecuente, persistir en el rechazo al presente de los triunfadores es una forma de resistencia -y de triunfo- de la memoria. La figura del antihéroe en los textos de Taibo, Sasturain u Oses, tiene entonces un doble aspecto: el fracaso es en ellos la dimensión de un triunfo ético-político.

Las formas de resolver la derrota y el trauma posterior parecen presentarse de modo diferente en los relatos femeninos y abandonar toda pretensión de heroísmo. La resistencia, la aceptación de la derrota y la asunción de la pérdida adoptan en los textos escritos por mujeres soluciones diferentes. Los antihéroes a la manera del relato policial no son en ellos frecuentes, antes bien las narrativas femeninas están más cerca de las figuras que resisten replegándose y se niegan, desde cierta "lejanía”, aislamiento o distancia, a incorporarse al mundo de los triunfadores. Quizá sea un ejemplo paradigmático en este sentido parte de la producción de Cristina Peri Rossi. Un cuento, “El arte de la pérdida” (incluido en Una pasión prohibida), produce por su título la inmediata tentación de asociarlo con Perder es cuestión de método y recuerda frases reiteradas a lo largo de esta novela como “[...]formular la estética de la más contemporánea de las artes: la de saber perder”. Sin embargo, el relato plantea un perdedor diferente: el protagonista se ha "replegado" y resiste en un ámbito puramente imaginario. La posibilidad de poseer un secreto, "el secreto de su identidad [pues] era hora de tener algo que nadie pudiera quitarle” (136), es la única alternativa que le queda. El hombre despojado de todo, que recuerda la frase "un fracasado sin vueltas” con que se definía al protagonista de El viaducto, no juega, a diferencia de éste, ningún rol antiheroico. La crisis económica a la que alude el texto se vuelve aquí metáfora de todas las pérdidas: “[T]e lo quitarán [...] ¿No te han quitado ya todo lo que tenías?” (138), le advierte un amigo. Es el secreto de su imaginaria identidad la única posesión que supone no le podrán quitar. Esa “inalienable posesión” se demuestra muy pronto inútil e insignificante; el despojo terrible incluye esa "identidad secreta", que no puede definir y ni siquiera sabe para qué sirve. Lo "inalienable” se diluye, se escurre "como el agua” y lo deja, sin secretos, porque “[q]uizás [...] ya le habían quitado su tesoro. Inadvertidamente, como había perdido las demás cosas, pero de una manera fatal, tan fatal como las otras pérdidas” (140). El protagonista, de modo opuesto a los personajes de Taibo, Gamboa, Sasturain y Sepúlveda, pierde "sin método ni convicción”, no lucha de forma alguna. Se repliega y acepta que la identidad es, “como las fortunas en Suiza”, algo que poseen pocos hombres, ${ }^{8}$ los triunfadores.

\footnotetext{
${ }^{7}$ Reyes Mate, siguiendo a Weber, propone una ética de la convicción que consiste en ser consecuente con los propios principios y actuar sin tener en cuenta las consecuencias que pudieran derivarse. Nótense aquí las coincidencias con la posición de Badiou.

8 Es interesante que el mismo personaje se plantee dudas sobre la posesión de ese "secreto maravilloso" por parte de las mujeres: "El artículo no decía nada específicamente acerca de las mujeres [...] ¿Debía suponer que ellas estaban también incluidas?” (138). Ser perdedor o triunfador, tener una identidad es una partida de hombres. Las mujeres (como puede observarse en los relatos masculinos) parecen estar fuera de juego. En todo caso, "si también era dueña de un secreto, equivalente al suyo, no lo sabía, y ahí estaba la diferencia” (139).
} 
Es decir, no tenemos aquí un antihéroe que resista; la pérdida se desplaza a lo privado y más íntimo -“el secreto que nadie conoce”- y concluye en aceptación o resignación. El desastre ha sido devastador (no le queda ni su identidad oculta) y el cuento, escrito en los ochenta, resulta así una sinécdoque y una lectura poco esperanzada de esos años. La resolución en el repliegue se complejiza en La nave de los locos. Novela publicada en 1984, puede leerse como una alegoría de la derrota y de los caminos que se abren después de ella. La descripción de "El tapiz de la creación” que escande todo el relato es, como se dice explícitamente, "una estructura que es una metáfora, sin dejar de ser por ello, también, una realidad” (21). Exilio, diáspora y repliegue definen el vagar sin rumbo preciso de personajes como Equis y Vercingetórix, y sus viajes, de los que, como el de la nave de los locos, no se puede volver. La pérdida, la pesadilla (y en este sentido los epígrafes de la novela cumplen a la perfección la tarea de orientar la lectura ${ }^{9}$ ) deja a los protagonistas desterritorializados: ${ }^{10}$ "siempre partimos del lugar donde hubiéramos sido eternos y felices” (109). Vagar, replegarse, encontrar, como en el tapiz

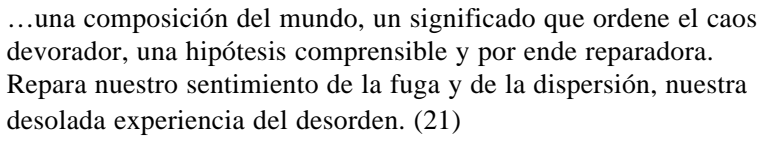

será la experiencia que les resta. Errantes, toda posible heroicidad se diluye en la búsqueda de un refugio (y las metáforas de éste abundan: el quiosco en el que Percival encuentra "perfectamente natural" protegerse, la isla, Pueblo de Dios). En cualquier caso, nunca será el sitio adecuado, como en los sueños de Equis en ese espacio “incómodo”, no se encuentra "la puerta de acceso [...] y nunca llego al lugar exacto" (173). Perdidos en ese sueño/pesadilla no hay lugar para el heroísmo en los protagonistas, o quizá mejor habría que aceptar que lo heroico consiste en esa capacidad de sobrevivir y resistir sin esperanzas.

Está claro que estos relatos de Peri Rossi dibujan figuras sin vocación de heroicidad; frente a la derrota, Equis o el protagonista sin nombre de "El arte de perder" no pretenden “enseñar a perder: con altura, con elegancia, con convicción” como propone el antihéroe de Sasturain (Manual 151). Sólo pueden reconstruir, como en el tapiz, la delicada trama, la armonía verificable "aún habiendo desaparecido casi su mitad, si no en el muro de la catedral, sí en el bastidor de la mente. Allí se despliegan los metros que faltan...” (21, la bastardilla es mía). Otro sesgo, tal vez otras formas de memoria y resistencia que pasan por la interioridad de estos personajes.

Sin embargo, es quizás una novela de la escritora chilena Alejandra Rojas la que más claramente establece un debate (o un diálogo) con los relatos de los autores mencionados

\footnotetext{
${ }^{9}$ En especial uno de ellos: "El matrimonio de la razón y la pesadilla que dominó el siglo xx ha engendrado un mundo cada vez más ambiguo”.

10 “Extranjero. Ex. Extrañamiento. Fuera de las entrañas de la tierra. Desentrañado: vuelto a parir. No angustiarás al extranjero. Pues. Vosotros. Vosotros. Vosotros. Los que no lo sois. Sabéis. Vosotros sabéis. Nosotros empezamos a saber. Cómo se halla. Cómo. El alma del extranjero. Del extraño. Del introducido. Del intruso. Del huido. Del vagabundo. Del errante” (10).
} 
en el comienzo de este trabajo. El beneficio de la duda, publicada en 1997, es su tercera novela y podría leerse como el reverso del sistema propuesto por los textos masculinos. Es un relato de y sobre perdedores, centrado en dos hombres y una mujer que sostienen una larga conversación e intentan comprender y recordar sus vidas, atravesadas por la historia chilena de los últimos veinte años. Como en el resto de los textos del corpus, la derrota se explica y se define en términos de historia política y los perdedores, por lo tanto, no sólo son antihéroes, sino también personajes que arrastran consigo la historia de su tiempo. El relato muy pronto establece una clara distinción entre los dos hombres y la mujer, Leonor: ellos son dos perdedores que, habiendo formado parte de los derrotados, apuestan a participar del nuevo estado de cosas, de esa democracia llamada transición “aunque la palabra transacción parecía cada día la más adecuada” (125). Este es el punto nodal en la trayectoria de los personajes masculinos; ellos han pasado de ser perdedores semejantes a los del resto del corpus a ser fracasados y puede aquí hacerse esa distinción, del mismo modo en que Agamben distingue entre "derrota y deshonra” (Medios, 113). La diferencia la marca el transigir, el ceder, "la mala conciencia y la abjuración con la memoria y la fidelidad" (114). Ese es el camino que toman los dos personajes masculinos de la novela y que los diferencia y "destierra” de toda posibilidad antiheroica. Octavio, el protagonista, que se presenta como "más derrotado imposible” y “en jirones” (28), refugiado en un hotel y un pueblo miserable porque "algo se le había fracturado por dentro” (35), hace pensar a primera vista en un antihéroe similar a los ya mencionados anteriormente. Junto con su amigo Héctor, su doble y contracara al mismo tiempo, han llevado adelante un diario, La verdad, espacio de resistencia que ha ido deslizándose a una neutralidad muy asemejante a la claudicación. La probable compra del periódico por el Opus Dei, la huida de uno y el colaboracionismo del otro exponen la magnitud del desastre. El periódico es la sinécdoque de estas trayectorias: resistencia, neutralidad, transigencia y derrota. Los dos "héroes" han aceptado de algún modo colaborar; por la tanto ya han pasado de la condición de perdedores que resisten a la de fracasados. El relato está atravesado por las marcas de esta derrota que al principio se pueden confundir con formas de resistencia aunque pronto se muestran estériles productos del ceder y de la falta de fidelidad a la memoria.

Por el contrario, la figura femenina no actúa jamás como derrotada ni como heroína; su historia es otra metáfora de la época: hija de un desaparecido, su búsqueda y posterior aceptación de la pérdida no representan ninguna forma de heroísmo. Pragmática hasta la crueldad, “víctima que se resiste a serlo”, Leonor se convierte en una sobreviviente y se repliega porque “el horror no es sino una realidad más profunda que se atisba a través de una fisura de la rutina” (155).

Para los dos personajes masculinos parece insoportable no participar, no alcanzar alguna forma de éxito y perseverar en el distanciamiento que implica no pactar de algún modo con el poder. Octavio resuelve sus pesadillas de escape y la "conciencia de su naufragio” (83) con una huida a partir del descubrimiento de un manuscrito -escrito por una mujer-que lo revela como culpable. Sorprende saber que nadie ha leído ese escrito; ¿de qué es culpable entonces el personaje? Si elige la desintegración luego de una batalla perdida dentro de la propia conciencia es porque "les había fallado pero no del modo que 
todos pensaban"11 (239). La derrota, la "falla” que, insiste, "pasaba por el espacio material de sus sueños" (240) es entonces otra; consiste, justamente, en una traición sostenida como director de La verdad que ya se ha vuelto una mentira. ${ }^{12}$ Por eso es significativa la escena de pánico en que domina un recuerdo infantil: una serie de espejos curvados le devuelven una imagen cada vez más grotesca, hasta que en el último, el espejo plano, ya no ve nada, allí sólo está la vivencia de "la desviación, de la inexistencia” (209). Desviarse y fracasar ha sido la ruta que tomaron los protagonistas masculinos: es decir, engañar y dejarse engañar, olvidar, ceder y perder su identidad.

Son las mujeres las que establecen la diferencia con los mecanismos masculinos de autoengaño. Leonor no juega al heroísmo ni al fracaso, pero su repliegue no impide la acción; ella es la que en el epílogo actúa y salva a Octavio, en la escena de un falso interrogatorio ante un juez grotesco, escena que evoca como una dolorosa parodia la falta de justicia y la lenidad de los jueces durante la dictadura. Ella es la que, aún a costa de la verdad que jamás se alcanzará, permanece fiel a su verdad, aunque no crea en las victorias ${ }^{13}$ ni en la posibilidad de saber. Sin ilusiones, sabe ya que la pérdida no tiene reparación y que todo intento de olvido o proyecto triunfalista está destinado al fracaso. Y esto la une a la otra figura femenina del texto, Irene, el personaje ausente que desencadena la crisis del protagonista masculino. Ella es la autora del manuscrito-profecía sobre su fracaso y claudicación, así como de otros extraños y ambiguos textos que inquietan a Octavio; en particular, el dedicado al mono de las Antillas, prisionero que "[n]o se escapaba, porque entre la libertad y el miedo se refugiaba en la estrecha seguridad de su árbol.” (99) Nada sabemos acerca de ella, excepto que cualquiera sea el cierre de su manuscrito anticipatorio y con final abierto, “ganaba Irene al perder” (286), y esto, claro, marca la diferencia con Octavio, su contrafigura.

En realidad las dos mujeres son una nueva clase de heroínas perdedoras; no pretenden victorias porque no creen en ellas y dejan sin escapatorias ni respuestas los interrogantes y los discursos de los dos personajes masculinos. Estos, luego de haber sido héroes perdedores fracasan al buscar una salida "negociada", un camino de concesiones, porque transigir es traicionar el recuerdo y las fidelidades: esa es la falla (la deshonra) de los protagonistas. El texto no abre así ninguna esperanza de consuelo para ellos. En verdad, son sombras, fantasmas melancólicos, en los que se ha diluido su identidad antiheroica.

\footnotetext{
${ }^{11}$ Es sintomático que nadie comprenda el motivo de su huida y se desarrollen toda clase de conjeturas: en la sociedad posdictatorial la "adaptación" al medio es la regla. Como el mismo Octavio reconoce, hubiera podido "seguir jugando al héroe" (241).

${ }^{12}$ El periódico y los protagonistas tienen una historia paralela: soportó la censura, fue la imagen de la resistencia, pero en la transición han comenzado a ceder y olvidar:

-Nada, eso hiciste. Ni por los vivos, ni por los muertos, ni por el diario.

-Y qué querías que hiciera?

-No sé, Octavio. Algo más digno. Han pasado cuatro años y ¿qué ha cambiado? [...] La democracia se ha vuelto un baño de oro para cubrir la indecencia. Pero dorada y todo, la mierda nos está ahogando. -Y todo eso es mi culpa.

-Quizás. Empieza a ser tu culpa si no lo condenas (226).

13 “Para ese minuto de poder, toda una vida de espera. Sintió una profunda decepción, sólo decepción, tan poca cosa una victoria” (284).
} 
Enfrentados a las opciones ético-políticas que se abren en la posdictactura, el camino que han tomado no permite al arrepentimiento. Como señala Agamben, “[... ] el arrepentimiento es la menos fiable de las categorías morales [...]” (106); del mismo modo, el manuscrito profético no deja alternativas a quien "transó"; sólo le queda el fracaso; se trata de un camino ya escrito y sin retorno, un vaticinio que se cumple inevitablemente.

De este modo, el texto de Rojas se incorpora al corpus a la vez que debate con los relatos masculinos, funciona como su contracara o, mejor, da una vuelta de tuerca al sistema: los protagonistas de la novela forman parte de aquellos perdedores que no permanecieron distantes y ajenos al triunfo enemigo. Creyeron poder participar sin plegarse a la victoria de los otros. El riesgo por haber aceptado cualquier clase de pacto y olvido los lleva a un fracaso peor que la muerte. Por el contrario, la figura femenina se sostiene -otra vez- en el repliegue, en un ejercicio cotidiano de sobreviviencia, de resistencia sin compasión, lejano a toda pretensión de heroísmo.

Es interesante vincular la novela de Rojas El daño de Andrea Maturana, publicada en Chile también en 1997. A primera vista no tiene conexión alguna con la de Rojas: el relato gira en torno a la reparación y la cura de ese daño; la protagonista debe remontar a través de la memoria y la palabra el horror de una herida imposible de borrar. Violación y abandono son aquí episodios de índole privada, son el secreto que deberá ser verbalizado para empezar a sanar. Si bien ninguna alusión a la pérdida histórica está explícita, es un texto de dolor y derrota aunque ésta transcurra en el ámbito personal, íntimo. Reparar “el daño”, la locura, la violación, la muerte, requiere un repliegue, una búsqueda individual, lejos de todo protagonismo. Probablemente se podría arriesgar, entre las muchas lecturas que la novela propone, esta búsqueda como metáfora de un intento de cura para un daño mayor, social e histórico.

En cualquier caso, los textos femeninos parecen estar desprovistos de alternativas heroicas. El antihéroe perdedor de los relatos masculinos se constituye en el resistir y no participar, pero, como ya se dijo, esta prescindencia lo convierte en un héroe excepcional. Orgullo de los elegidos, la validez de su gesto se sostiene en la afirmación de ese desafío que lo ubica en una instancia más elevada de triunfo. En definitiva, esta condición antiheroica lo transforma en un héroe perfecto. Por el contrario, los relatos escritos por mujeres no parecen creer en ninguna forma de heroismo como salida. Frente a la pérdida, El beneficio de la duda o La nave de los locos proponen otras formas de resistencia: reparar el daño, recuperar la memoria en un lento trabajo que comienza por la aceptación de lo irreparable.

Quizá sea la novela de José Donoso El jardín de al lado, paradigmática de esa narrativa que se afirma en la pérdida, la que logra representar las dos opciones, femenina y masculina, simultáneamente. Texto de exilio y derrota, la identidad del protagonista se conforma en la aceptación de esa pérdida, en un margen, en un "al lado”, que es sombra, pálido reflejo de un original remoto. Es significativo que esta condición se configure a través de su fracaso como escritor de una "novela-documento" sobre la propia experiencia histórica. Sólo parece ser posible hablar de la Historia (con mayúsculas) cuando se lo hace al sesgo, soslayando los hechos, por medio de metonimias como, en este caso, la frustración literaria del protagonista, incapaz de narrar lo ocurrido en forma "directa”. 
Aunque para este antihéroe “el único mundo coherente es el del fracaso” (132), ${ }^{14}$ la cita de Eliot que cierra el capítulo dos - “esperar sin esperanzas”"15 - lo incluye entre aquellos héroes perdedores que resisten. Su fracaso como escritor, su estar "al margen", tiene como contrapartida a su esposa, la narradora que se revela en el capítulo final y autora de la novela que no pudo escribir jamás el protagonista. Ella dará el primer paso "fuera del ámbito del fracaso" (257) y será la que construya un nuevo espacio, un sitio desde donde se persiste ya no en la derrota sino en la aceptación de la pérdida. La escritura, que surge en ese margen, en ese "jardín de al lado” y hace posible el duelo, permite también recuperar la propia identidad y la memoria. La narradora reconocerá entonces que no se trata de escribir la novela mediocre y exaltada "que describe una parte de cierta tragedia” y quedará en el olvido (como la de su marido), sino de "asumir el tono menor [que] fue, tal vez, mi salvación”. (273) Esa parece ser la línea divisoria entre los dos protagonistas y el punto crucial de la diferencia: la figura femenina se afirma en el repliegue y en el silencio luego del desastre, no asume ningún rol heroico o antiheroico. Antes bien, la resistencia y la memoria surgen del mismo trabajo de duelo para esta narradora final de El jardín de al lado, la única en definitiva que logra dejar su huella y recuperar su historia:

Escribí mis quejas en mi diario, tan desgarrador que ahora no me atrevo a releerlo; pero al releerlo entonces para escarbar en mi rencor, y al volver y volver a escribir esas páginas, y darles vueltas y más vueltas, fui como depurándolo todo [...] hasta darme cuenta de que para que este examen tuviera fuerza de realidad era necesario que yo construyera algo fuera de mí misma, pero que me contuviera, para "verme”: un espejo en el cual también se pudieran "ver" otros, un objeto que yo y otros pudiéramos contemplar afuera de nosotros mismos, aunque todo lo mío sea, ahora, en tono menor. (263, énfasis mío)

Así, el tono menor sin heroísmos parece ser el diseño que han dibujado para sus representaciones de resistencia y memoria algunas narraciones femeninas. No deja de ser interesante que sea una novela de Donoso la que proponga ambas alternativas través de sus dos protagonistas.

La memoria es, en todos los casos, una forma de desafío a las versiones exitosas de la historia y se sostiene por un ejercicio continuo de resistencia: afirmarse en el rol perdedor es asumir el recuerdo y proponer un espacio -imaginario, en la literatura- a la esperanza de justicia. Los relatos considerados plantean así una clara convergencia entre ética y política. Convergencia entendida como una práctica de lectura de la Historia y una posición frente a ésta, en la medida en que todo discurso se define -y nos define- en una elección, nos propone opciones ético-políticas y nos enfrenta finalmente con nuestra

${ }^{14}$ Las referencias a la derrota atraviesan el texto: "nada de lo que hacíamos dejaba la menor huella” (188), “¿Pueden ser tan totales las derrotas en una mañana como ésta?” (208).

${ }^{15}$ El fragmento de Cuatro cuartetos de T.S.Eliot citado ejemplifica el gesto de resistencia que define a todos los antihéroes mencionados:

...esperar sin esperanzas

Porque esperar sería esperanza de algo equivocado; esperar sin amor

Porque amar sería amor por algo equivocado; queda la fe,

Pero la fe y el amor y la esperanza no son más que expectación.

Esperar sin pensar, porque aún no estás maduro para el pensamiento [...] (115) 
capacidad de aceptación de la derrota. Asumir la pérdida, el camino de la resistencia y el rechazo a los vencedores y su presente es optar también por perseverar en la memoria: una forma de triunfo que está lejos de ser sólo una cuestión especulativa. Si esto es común a todo el corpus, los relatos femeninos (y las heroínas o antiheroínas) aportan una inflexión particular. Los antihéroes son en definitiva figuras heroicas, nuevo tipo de triunfadores éticos, que se proponen como una "aristocracia de perdedores", la de los que no han pactado con el poder. Las textos escritos por mujeres sostienen otras alternativas y confían poco en cualquier tipo de heroísmo, siempre parecido al éxito de algún modo. La memoria femenina parece creer en el repliegue y desconfiar de las distintas coartadas que permiten el consuelo. Para personajes como Leonor e Irene en El beneficio de la duda, para la protagonista de El daño (y también para la narradora de El jardín de al lado), resistir y recordar son cotidianos ejercicios solitarios, son una opción de vida que no claudica jamás. ${ }^{16}$ Quizás por eso se reiteran en varios textos las representaciones de la escritura femenina: a través de ella se realiza el duelo, se repara el daño, se sostiene la memoria, se combate el olvido, se castiga a los que ceden. La escritura, como una forma de acción en lo que he llamado "el repliegue" de estas figuras sustituye a la afirmación del gesto antiheroico de los relatos masculinos.

Extremos en su desencanto y en la pérdida de toda ilusión, los textos femeninos considerados proponen una alternativa diferente al resto del corpus, y quizá ésta sea la razón que hizo difícil reconocerlos, a primera vista, como parte de él. La misma apuesta a la resistencia y la memoria, pero una posición más radical en su desconfianza en la efectividad de las actitudes heroicas (o antiheroicas): sólo cabe en ellos recomenzar desde un espacio cotidiano distanciado, de extrañamiento y silencio, a reparar el dolor, a recordar el pasado y construir otro futuro.

\section{BiBLIOGRAFÍA}

Agamben, Giorgio. Estancias. La palabra y el fantasma en la cultura occidental. Valencia: Pre-textos, 2001.

Medios sin fin. Notas sobre la política. Valencia: Pre-textos, 2001.

Amar Sánchez, Ana María. Juegos de seducción y traición. Literatura y cultura de masas. Rosario: Beatriz Viterbo, 2000.

Avelar, Idelber. Alegorías de la derrota: la ficción postdictatorial y el trabajo del duelo. Santiago: Cuarto Propio, 2000.

Badiou, Alain. “La ética. Ensayo sobre la conciencia del mal”. Batallas éticas. Tomás Abraham, ed. Buenos Aires: Nueva Visión, 1995.

Bergero, Adriana J. y Fernando O. Reati, comps. Memoria colectiva y políticas de olvido. Argentina y Uruguay, 1970-1990. Rosario: Beatriz Viterbo, 1997.

Cerda, Carlos. Morir en Berlín. Santiago: Planeta, 1994.

Donoso, José. El jardín de al lado. Santiago: Alfaguara, 1996.

\footnotetext{
${ }^{16}$ Leonor, hija de un desaparecido, señala: “¿Tú necesitas saber, Octavio? Todos necesitamos, siempre. No hay un solo minuto, una sola cosa que no necesitemos saber. El problema es que a veces no queda más que creer. Esa es la desgracia” (285, énfasis de la autora).
} 
Gamboa, Santiago. Perder es cuestión de método. Bogotá: Editorial Norma, 1997.

Garber, Marjorie B., Beatrice Hanssen y Rebecca L. Walkowitz. The Turn to Ethics. New York: Routledge, 2000.

Hoyos Vásquez, Guillermo y Ángela Uribe. Convergencia entre ética y política. Bogotá: Siglo de Hombre Editores, 1998

Mate, Reyes. La razón de los vencidos. Barcelona: Anthropos, 1991.

Maturana, Andrea. El daño. Santiago: Alfaguara, 1997.

Oses, Darío. El viaducto. Santiago: Planeta, 1994.

Peri Rossi, Cristina. La nave de los locos. Barcelona: Seix Barral, 1989. Una pasión prohibida. Barcelona: Seix Barral, 1986.

Reati, Fernando O. Nombrar lo innombrable. Violencia política y novela argentina: 1975-1985. Buenos Aires: Legasa, 1992.

Rojas, Alejandra. El beneficio de la duda. Buenos Aires: Seix Barral, 1997.

Sasturain, Juan. La mujer ducha. Buenos Aires: Sudamericana, 2001. Manual de perdedores 2 vol. Buenos Aires: Legasa, 1985.

Scheines, Graciela. Las metáforas del fracaso. La Habana: Casa de las Américas, 1991. Sepúlveda, Luis. Nombre de torero. Barcelona: Tusquets, 1994.

Taibo II, Paco Ignacio. Arcángeles. Doce historias de revolucionarios herejes del siglo Xx. México: Planeta, 1998.

Primavera pospuesta. Una versión personal de México en los 90. México: Joaquín Mortiz, 1999.

Vázquez Montalbán, Manuel. Historias de política ficción. Barcelona: Planeta, 1987. 